\title{
Downward Bias of the Russian Output Statistics and Its Microeconomic Foundations
}

\author{
Masaaki Kuboniwa Hitotsubashi University
}

\section{Introduction}

For the years 1992-1994 the economic situation in Russia has been very difficult, due to the intrinsic problems arising in the reconstruction of the State itself as well as the usual difficulties associated with the process of the transition to a market economy in general.

The macroeconomic difficulties of the Russian situation, including continuous industrial depression, high inflation rates, large budgetary deficits and non-functioning financial markets, are fairly well understood. However, the downward bias of the official statistics and the microeconomic foundations behind the veil of ongoing macroeconomic disequilibria have not yet been fully discussed, owing to the very uncertainty of statistics of economic performance and to continuous changes in state regulations.

This paper intends to provide some results of preliminary observations on the intrinsic problems of the Russian macroeconomic statistics, including a markedly downward bias of industrial production caused by the tax evasion activities of industrial firms, which, in turn, are partly caused by high inflation. These observations will provide a better understanding of the importance of macroeconomic stabilization policy for structural reforms because, among the disequilibria of a national economy, inflation reflects an economic and societal crisis regarding monetary instruments for the market and the preservation of wealth and hyperinflation throws into confusion the behavior of the economic agents.

\section{From Upward Bias to Downward Bias of Industrial Output}

In the Soviet era, as was pointed out by many economists, including Seliunin-Khanin and Treml, the official statistics of industrial production and national income suffered a general and continuous upward bias. This upward bias was mainly brought about by the traditional command system associated with its intrinsic incentive system, namely the distribution of bonuses, input requirements and output targets according to the extent of fulfillment of production plans. In this situation Soviet firms sent to the planning and statistical authorities reports which overestimated output performance and 
input needs.

In the process of transformation both the command system and its associated incentive system disappeared. The scope of governmental regulations largely shifted to macroeconomic fiscal and monetary policy. In this situation, facing high inflation rates, firms began to change their reporting strategies. Namely, they began to send reports underestimating output and income to the statistical authority (Goskomstat RF) and tax offices. We can easily imagine that this resulted in a markedly downward bias of industrial production. This implies that the industrial output in Russia did not fall as much as shown by the official statistics, even if it indeed showed a remarkable drop.

Let us first show the downward bias of industrial output by looking at the inconsistency between the official figures for the output of the electric power sector and other industrial outputs. The official figures for output and consumption of electric power are rather reliable because they are hardly affected by aggregation, transportation, and sale through the "second" channels. Although natural gas also has such characteristics, we base analysis only on electric power because of the lack of adequate input-output data.

Let

$\mathrm{x}:=$ gross domestic output of the electric power sector;

$a:=$ the electric power sector's own input coefficient (use of domestically produced electric power needed to produce one unit of electric power); $\mathrm{H}:=$ total intermediate demand for domestically produced electric power by all the sectors other than the electric power sector;

$\mathrm{Y}:=$ total final demand for domestically produced electric power.

Using these notations, we are able to formulate an input-output equation of the electric power sector for the year $t$ as follows:

$$
x(t)=a(t) x(t)+H(t)+Y(t) .
$$

Further, define $g_{H}$ and $g_{Y}$ as the growth rate of $H$ and of $Y$, respectively, from $t$ to $(t+1)$, and we have for the year $(t+1)$

$$
x(t+1)=a(t+1) x(t+1)+\left(1+g_{H}\right) H(t)+\left(1+g_{Y}\right) Y(t) \text {. }
$$

Solving Eq.(1) and Eq.(2) for $x$, then

$x(t)=[1-a(t)]^{-1}[H(t)+Y(t)]$

and

$x(t+1)=[1-a(t+1)]^{-1}\left[\left(1+g_{H}\right) H(t)+\left(1+g_{Y}\right) Y(t)\right]$.

Here let us employ a traditional "Leontief" assumption of input coefficients: $a(t+1)=a(t)$.

Define $g_{x}$ as the growth rate of $x$ from $t$ to $(t+1)$, and it follows from Eq.(3) and Eq.(4) that 


$$
g_{x}=[x(t+1)-x(t)] / x(t)=g_{H} k(t)+g_{y}[1-k(t)]
$$

where

$$
k(t):=H(t) /[H(t)+Y(t)]
$$

When we assume that all the input coefficients, $a^{i j ' s, ~ a r e ~ c o n s t a n t ~ o v e r ~}$ the periods, $\mathrm{g}^{\mathrm{H}}$ also shows the average growth rate of domestic outputs other than electric power. So, roughly speaking, the general growth rate of industrial outputs would locate on the neighborhood of $g_{H}$ if we could assume that the average growth rate of material production sectors (construction, agriculture, transport and communications, trade and other material branches) other than industrial sectors is close to that of the industrial sectors.

Employing the relationship Eq.(6) and the official input-output data (noncompetitive type), we will be able to check the validity of the official growth rate of industrial output.

We can derive a table from I-O data that shows how electric power was distributed to each sector, namely to what extent each sector demanded electric power, for the years 1989-1991. The MBMW sector shows the greatest demand ratio, $12-14 \%$, among the industrial sectors, followed by the chemical industry sector, $11-12 \%$, the oil and gas sector, 6-7\%, and the nonferrous metallurgy sector, 5-6\%. Other than industrial sectors, the transportation and communication sector shows the greatest demand ratio, 6-7\%. In regard to final demand, the consumption demand ratio for electric power shows 21 $23 \%$. As investment and inventory demand for electric power does not exist, a marked reduction in investment and an inflated increase in stocks that have been seen in Russia can not directly influence the real growth rate of electric power.

Regarding the table, it should be noted that the own demand ratio $(=$ own input coefficient) of the electric power sector shows a remarkable change in 1991. This does not correspond to the Leontief assumption shown by Eq.(5). [Price change in electric power does not affect its own input coefficient.] However, as the own input coefficient of electric power in 1991 still shows a rather small value and [1 - a(1991)], 0.98 is very close to [1 - a(1990)], 0.99, use of Eq.(5) can be allowed as an approximation. It should also be noted that in 1991 the domestic trade sector and nonproductive consumption show a marked increase in demand ratios, owing to the development of (semi) private economic agents.

Computing values of parameters $a, k$ and (1-k), required for use of Eq.(6), we can approximate Eq.(6) by the following specified equation:

$$
\mathrm{g}_{\mathrm{x}}=0.74 \mathrm{~g}_{\mathrm{H}}+0.26 \mathrm{~g}_{\mathrm{Y}} \text {. }
$$

Using the official physical growth rates for 1992 and the official input- 
output table for 1991 , we obtain $\mathrm{g}_{\mathrm{H}}=-20 \%$. In order to satisfy the official statistics $\left(g_{x}=-4.7 \%\right.$ ), $g_{Y}$ should show an unrealistically high value, say $39 \%$. Even if nonproductive consumption of electric power shows a remarkable increase in 1992 due to the presence of privatization and new business, this high value can not be supported. Further, when this is true, changes in parameter, k, can not support the industrial situation in 1993 and 1994. More plausible values for $g_{Y}, 10 \%, 0 \%$ and $-10 \%$, yield growth rates of electric power much lower than the official figure.These discussions suggest that the official figures, other than the figure for electric power in the tale, suffer seriously from a markedly downward bias.

When we fix $g_{x}$ for 1992 as the official figure, $-4.7 \%$ in Eq.(7), we have $g_{H}$ $=-6.4 \%$ for $g_{Y}=0 \%$ or $g_{H}=-9.9 \%$ for $g_{Y}=10 \%$. Hence, roughly, we may conclude that the actual overall growth rate of industrial output for 1992 should be within the range of between $-6 \%$ and $-10 \%$, much higher than the official value. In the same manner, the growth rate of industrial output for 1993 should be within the range of between $-7 \%$ and $-11 \%$, which is much better than the official figure, $-16.2 \%$.

The growth rate of the electric power sector over the previous period is $-9 \%$ for 1994 . So the actual growth rate of overall industrial output for the first nine months of 1994 would be between $-9 \%$ and $-12 \%$ much higher than the official figure, $-20.9 \%$ (-22.8\% for the large and medium size industries).

Thus, we can state that industrial output for 1992, 1993 and dropped at most by $10 \%, 11 \%$ and $12 \%$, respectively. However, it should be noted that the situation for industrial output has been getting worse and at best is very difficult.

\section{Microeconomic Foundations of the Downward Bias}

Let us next consider the microeconomic foundations of the downward bias of industrial output.

Firstly, this downward bias is based on the presence of hyperinflation which is characterized by predominance of speculative behaviors with a marked fall of productive investments on behalf of private agents and by acceleration in the process despite the efforts made by the governmental authorities.

Under hyperinflation rates of over $6 \%$ per month (yearly $100 \%$ ) a firm with rather long cycle of production would earn rather high profit at the enterprise accounts than at the industry production account without inflation. However, taxes are levied on this nominal profit at a high rate of over $30 \%$. Using after-tax profits the firm has to compensate the loss owing to the inflation of material inputs. 
Let us show this by a simple formal analysis.

Assume that for the production, $x(t)$, in the $t$-th period the firm has to buy a material input, $k(t-s)$, at the (t-s) period in the price of $q(t-s)$. Letting $p(t)$ be the price of the firm's output, then the enterprise accounts record at the $t$ th period: Production - Materials used

$$
=\mathrm{p}(\mathrm{t}) \mathrm{x}(\mathrm{t})-\mathrm{q}(\mathrm{t}-\mathrm{s}) \mathrm{k}(\mathrm{t}-\mathrm{s})[\mathrm{i}=\mathrm{Z}]
$$

whereas the production account of the industry without inflation is:

Production - Intermediate inputs

$=\mathrm{p}(\mathrm{t}) \mathrm{x}(\mathrm{t})-\mathrm{q}(\mathrm{t}) \mathrm{k}(\mathrm{t}-\mathrm{s})\left[:=\mathrm{Z}^{*}\right]$.

Then the loss due to the inflation of material inputs amounts to: $q(t-$ $\mathrm{s}) \mathrm{k}(\mathrm{t}-\mathrm{s})$ - $\mathrm{q}(\mathrm{t}) \mathrm{k}(\mathrm{t}-\mathrm{s})$. If taxes are not levied on the profit, $Z$, the firm can compensate the loss by the extra profit due to the inflation, which amounts to:

$Z-Z^{*}=q(t) k(t-s)-q(t-s) k(t-s)$.

However, if taxes are levied on the profit at a rate, $u$, and hyperinflation prevails, then the firm can not fully make up for the loss. The difference between the after- tax profit at the enterprise accounts and that at the production account of the industry amounts to:

$(1-u)\left(Z-Z^{*}\right)=(1-u)[q(t)-q(t-s)] k(t-s)$.

Therefore, as a result, the deficit for compensation of the loss amounts to $\mathrm{u}[\mathrm{q}(\mathrm{t})-\mathrm{q}(\mathrm{t}-\mathrm{s})] \mathrm{k}(\mathrm{t}-\mathrm{s})$. The greater the tax rate and inflation rate are, the larger this deficit becomes.

Thus, under proper functioning of the taxation system, hyperinflation is a threat to even a simple reproduction of the firm. To survive, or to retain more of its own profits, the firm would tend to send to the public authorities underestimated reports on production and pre-tax profit. Indeed, manufacturing firms with rather long production cycle (firms producing watches etc.) complain of these inflation taxes and government tax policy, while firms with very short production cycle (firms producing chocolates etc.) do not suffer this kind of inflation tax. [Based on the author's interviews with managers of "The First Watch Factory", "The Second Watch Factory" and "Red October Chocolate Factory" in Moscow at the end of 1993.]

Secondly, not only firms with long cycles of production but also other firms suffer inflation of durable equipment price and relative price distortions such as a higher increase in prices of fuels and transportation. Every firm also has to deal with a marked increase in wages. In order to cover increasing costs and prepare for the expected difficulties, firms would like to avoid taxes as much as possible. Thus underestimated reports on outputs become a nationwide phenomena owing to inflation.

Thirdly, the Russian Federal Government (the central government) has 
needed to increase revenues as much as possible under the decentralized system in order to repay the external debt burden accumulated in the former centralized system, and to meet with needs of the social safety network and demand by the industry and agriculture sectors. Under the prevailing decentralized taxation-budget system local governments also needed to increase revenues to meet local needs. Under hyperinflation a high rate of profit tax apparently reduces the possibility of investment. However, the tax authorities does not rely on the Goskomstat statistics. Further, they can easily collect a large amount of taxes from large scale of industrial firms, while they face serious difficulties in collecting taxes from a great number of new and/or small firms in the service sector. Thus the tax authorities continue to maintain a high profit tax policy. Firms, in turn, continue to try to evade taxes. This game between the general government and the firms can not end until hyperinflation ends and the financial infrastructure develops sufficiently enough to meet preconditions required by a reasonably well-functioning market economy.

Lastly, it should be pointed out that firms' reports for industrial production statistics can be made use of for other purposes, including taxation, in Russia. On the contrary, by law in Japan tax offices do not have access to firms' industrial output reports sent to MITI so that MITI can compile indexes of industrial outputs reflecting the actual production level in a well defined manner.

\section{Concluding remarks}

When we consider the microeconomic foundations of the Russian macroeconomy, we need, first of all, a better understanding of its macroeconomic performance. In this paper, we described the actual situation of the macroeconomy, investigating the inconsistencies in the official statistics and the behavior of economic agents. By performing this preliminary task we are better able to reconcile various different perceptions of the Russian economic situation: that the Russian economic performance is much better than indicated by the official figures, and that the general situation is far from good; or a perception that relies heavily on the macroeconomic stabilization policy, and another that makes much of structural reforms.

\section{References}

Cohen, D.(1994), "Economic Transformation in Russia," Economics of Transition,Vol.2, No.2, pp.259-262. 
Gavrilenkov, E. and V. Koen, "How Large Was the Output Collapse in Russia?," IMF Working Paper, November.

Kuboniwa, M.(1994) "The Structure of Russian Foreign Trade in Transition," Hitotsubashi Journal of Economics, Vol.35, No.2, pp.73-94.

_ (1995a) "From Upward to Downward Bias of Industrial Production," Financial Markets, Jan.-Feb. pp.6-11.

__ (1995b) "Al'ternativnaia otsenka tempov spada promyshlennogo proizvodstva v Rossii na osnove modeli 'zatraty-vypusk'", Finansovye rynki, Ianvar'-Fevral'.

Kushnirsky, F.(1989), Growth and Inflation in the Soviet Economy, Boulder. Makarov, V.(1994), "Dual Economy in Russia Today," The Economic Review (Keizai Kenkyu), Vol. 45, No.2, pp.117-125.

Sapir, J.(1994), "What's going on in Russia," Economics of Transition. Vol.2, No.2, pp. 255-259.

Seliunin, V. and Khanin, G.(1987), "Foxy Figures (Lukavaia tsifra)," The New World (Novyi mir), No.2 (In Russian).

Treml, V.(1988), "Perestroyka and Soviet Statistics," in The Impact of Gorbachev's Policies on Soviet Economic Statistics, Washington D.C. 